DOI: $10.14451 / 1.192 .198$

\title{
РАЗВИТИЕ КОНЦЕПЦИИ БИЗНЕС-МОДЕЛИРОВАНИЯ
}

\author{
(c) 2020 Удальцова Наталья Леонидовна \\ кандидат экономических наук, доцент департамента Менеджмента и инноваций \\ факультет «Высшая школа управления» \\ Финансовый университет при Правительстве Российской Федерации, Россия, Москва \\ E-mail: udaltsova.nl@yandex.ru
}

В статье рассматривается и исследуется концепция бизнес-моделирования, ее актуальность на современном этапе развития предпринимательства. Автором выявлены факторы, определившие формирование и развитие концепции бизнес-моделирования. Проанализирована классификация онлайновых бизнес-моделей.

Ключевые слова: бизнес-модели, инновации, классификация бизнес-моделей

\section{Введение}

Современный скоростной мир значительнее меняет экономику, чем 10-20 лет назад. Скорость прогресса и появление новых решений выросли многократно, в результате многие компании сталкиваются с новыми вызовами инновационного развития, вынуждены внедрять новые идеи и технологии, чтобы оставаться конкурентоспособными. Сейчас даже крупнейшие компании вынуждены конкурировать не только друг с другом, но и с молодыми быстроразвивающимися компаниями.

Вследствие меняющихся рыночных условий, начиная с конца 20 века, возникла новая концепция, бизнес-модель, как один из фундаментальных драйверов для создания, поддержания и расширения конкурентного преимущества. Осознание того, что компании создают стоимость неодинаково и что особенности каждой бизнес-модели оказывают существенное влияние на результаты деятельности, постепенно привлекло значительное внимание к этой концепции, о чем свидетельствуют распространение разнообразных механизмов и инструментов для разработки бизнес-моделей и их совершенствования, а также использование бизнесмоделей в компаниях.

\section{Основная часть}

Растущее внимание к концепции бизнесмодели основано на сочетании двух основных факторов, возникших за последние 25 лет и радикально изменивших конкурентную среду. Первый фактор - это наступление эры цифровых технологий, информационных и коммуникационных технологий, которые кардинальным образом изменили традиционную схему веде- ния бизнеса и создали новые пути создания стоимости. Второй фактор - динамичное развитие рынков с тенденцией к глобализации и интеграции в общее экономическое пространство, которое заставляет компании преобразовывать и улучшать существующие принципы ведения бизнеса.

Итак, историческое зарождение понятия бизнес-модель компании и необходимость ее использования связано со следующими объективными причинами:

1. Необходимость постоянного мониторинга деятельности компании. В современном бизнесе анализ деятельности компании и принятие эффективных управленческих решений невозможно без построения соответствующей бизнес-модели.

2. Рост информационных технологий. Успех бизнеса без использования передовых информационных технологий на сегодняшний день практически невозможен.

3. Необходимость систематического прогноза возможных кризисных ситуаций в компании. В современном бизнесе оценка платежеспособности компании и анализ эффективности ее деятельности требует пристального исследования основных бизнес-процессов, оказывающих влияние на финансовые показатели.

Анализируя теоретические и практические аспекты концепции использования бизнесмоделей, стоит обратить внимание на две основные проблемы. Первая проблема состоит в том, что многие управленцы компании не понимают в действительности текущую бизнесмодель компании или имеют смутное представление о ней и не уделяют этому должное внимание. Стоит отметить, что так или иначе 
у каждой компании формируется своя бизнесмодель независимо от того была ли она задумана и спроектирована заранее менеджерами или сложилась у компании случайным образом. Современный бизнес невообразим без использования бизнес-модели. Для предпринимателей и менеджеров важно понимать сильные и слабые стороны компании, иметь представление о том, что необходимо изменить в бизнесе, а что важно сохранить и приумножить. Поэтому без формирования собственной модели поведения ни один бизнес не сможет оставаться конкурентоспособным в долгосрочном периоде.

Вторая проблема связана с тем, что среди исследователей и ученых нет единого определения понятия «бизнес-модель». Стоит отметить, что бизнес-модель - это относительно новая концепция современного бизнеса и стратегического управления. Даже учитывая значительный прогресс в исследованиях концепции бизнесмодели, но из-за отсутствия четкого определения понятия «бизнес-модель», анализа и методологии ее разработки существенно затрудняют все возможности для реального использования.

Термин «бизнес-модель» включает в себе понятие «бизнес» как деятельность по предоставлению товаров и услуг с необходимым включением аспектов по финансам, коммерции и технологии и понятие «модель» как схематизированное описание процесса или объекта. А.Остервальдер объединил два понятия и получил термин «бизнес-модель» как концептуальный инструмент. Объединив два слова, А.Остервальдер дает общее определение: бизнес-модель - это концептуальный инструмент, содержащий набор объектов, концепций и их взаимосвязей, с целью выражения бизнеслогики конкретной фирмы.

Термин «бизнес-модель» многогранен, поэтому четкого определения ему не дают. Однако существует мнение как описать бизнес-модель в рамках механизма реализации компании своих стратегических планов в создании и фиксации ценности. Концепция бизнес-модели может рассматривать компанию в совокупности по основным стратегическим элементам, включающим ценностное предложение, наряду с партнёрами, капиталом и действиями, которые существенным образом влияют на разработку исключительно ценностного предложения, а также целевыми клиентами, каналами и иными взаимосвязями, которые необходимы для привлечения уже самих клиентов. Следовательно, концепция бизнес-модели может позволить понять процесс создания стоимости, а также определить факторы, которые возникают при реализации стратегии и будут влиять на ее стоимость. Поэтому исследование и развитие сущности концепции бизнес-моделирования имеет прикладное значение для роста и повышения конкурентоспособности компании и является актуальным вопросом для понимания со стороны предпринимателей и менеджеров.

Развитие информационных технологий также определило повышенный интерес к этой теме во второй половине 1990-х годов. Однако понятие «бизнес-модели» остается открытым, но исследования по поиску определения продолжаются. Ученые первого направления определяют бизнес-модель в качестве абстрактного понятия, по способу создания, реализации товара конечному потребителю $[12,4,6]$. Ученые второго направления исследуют больше концепт самого бизнеса [13]. Преодолеть сложность изучаемого процесса и свести ее к уровню способному дать необходимое понимание и восприятие - является прерогативой современных ученых при анализе основных элементов бизнес-модели и различных отношения между ними. Как пример можно привести исследования Александра Остервальдера и Ива Пинье и работы Клэйтонас Маглбис Кристенсена и Хеннинга Кагерманна, где не только дается определение бизнес-модели, но и подвергаются анализу все элементы, существующие в данной модели. При этом важно отметить, что состав и количество элементов внутри данных моделей (количество колеблется от 5-9), автор определяет по своему усмотрению. Реальные примеры использования бизнес-моделей и исследование конкретной ситуации рассматривает третье направление ученых. Последователи третьего направления применяют бизнес-модель для измерения успешности бизнеса таких компаний как Tayota, Xerox, Dell, Zara, Apple и прочеe.

Определения бизнес-моделей, которые были положены в основы выделенных трех направлений, представлены в таблице 1.

В русскоязычной литературе наиболее полный анализ определений и понимание концепции бизнес-моделей представлен в работах Стрекаловой Н.Д., Климановой Д.Е. и Третьяк О.А. [7, 14]

Ряд исследователей» таких как А. Остервальдер, И.Пинье и Ч.Туччи, а также К.Соммеррок, 
Таблица 1. Понятия концепции бизнес-моделей

\begin{tabular}{|l|l|}
\hline \multicolumn{1}{|c|}{ Автор } & \multicolumn{1}{c|}{ Понятие бизнес-модели } \\
\hline Ч. Ким, Р. Моборан & $\begin{array}{l}\text { Бизнес-модель - это кривая ценности, отображающая, каким способом компания } \\
\text { будет удовлетворять потребности клиента по разным критериям. }\end{array}$ \\
\hline Д. Дебелак & $\begin{array}{l}\text { Бизнес-модель для инвесторов является способом оценки эффективности вло- } \\
\text { женного капитала. Но для менеджера бизнес-модель - это инструмент развития } \\
\text { компании при любых рыночных условиях. }\end{array}$ \\
\hline К. Кристенсен & $\begin{array}{l}\text { Бизнес-модель состоит из следующих связанных между собой элементов: формула } \\
\text { прибыли, потребительская ценность продукта, ключевые процессы и ключевые } \\
\text { ресурсы. }\end{array}$ \\
\hline $\begin{array}{l}\text { А. Остервальдер } \\
\text { И.Пинье }\end{array}$ & $\begin{array}{l}\text { Бизнес-модель представляет собой процесс того, как компания делает деньги. } \\
\text { Бизнес-модель отражает ценность, которую компания доносит для своих потреби- } \\
\text { телей, различные способности компании, содержит перечень элементов, необхо- } \\
\text { димых для поставки ценности потребителям, отражает взаимосвязь капитала для } \\
\text { поступающих денежных потоков. }\end{array}$ \\
\hline г. Чесборо & $\begin{array}{l}\text { Бизнес-модель - это главный способ компании для создания получения опреде- } \\
\text { ленной ценности и прибыли. }\end{array}$ \\
\hline К. Маркидес & $\begin{array}{l}\text { Бизнес-модель содержит в себе ответы на следующие вопросы: кто наша целевая } \\
\text { аудитория? Какие продукт ценны для нашей аудитория и какова их позиция на } \\
\text { рынке? Как мы сможем эффективно донести эту ценность до потребителя? }\end{array}$ \\
\hline
\end{tabular}

АрайЮ.Н. выделяют пять основных этапов в эволюции понимания концепции «бизнесмодель»:

Этап 1. Определение и классификация бизнес-модели.

Этап 2. Выделение компонентов бизнесмодели.

Этап 3. Анализ компонентов как элементов всей системы.

Этап 4. Разработка категорий и базовых моделей.

Этап 5. Разработка специальных инструментов для анализа понятия бизнес-модели и применения концепции бизнес-модели.

Стоит отметить, что на сегодняшний день формируется 6 этап -трансформация бизнесмодели в новые улучшенные формы и разработка инструментов адаптации бизнес-моделей во внешней среде.

Также мы должны знать, что бизнес-модель компании и конкурентная стратегия - это совершенно два разных понятия. Ролевая позиция бизнес-модели заключается в описании сочетаемости и взаимосвязи происходящих бизнес-процессов в компании, а конкурентная стратегия задается вопросом каким образом обеспечить превосходство над своими конкурентами.

Бизнес-модель как источник конкурентного преимущества, должна включать в себя нечто большее, чем как просто логичный способ ведения бизнеса. Клиентоориентированность - важнейшая черта бизнес-модели. Нужно добавить, что бизнес-модель должна быть уникальной и в то же время пластичной, чтобы избегать нарушения отношений как с важными клиентами, так и с поставщиками и партнерами.

Бизнес-модель имеет ряд положительных свойств.

1. Способность выработки пошагового плана развития компании.

2. Способность понять структуру бизнеса, функций компании.

3. Способность дать ответ на вопрос: кто и в какой роли выполняет бизнес-процессы, в какой последовательности содержатся бизнеспроцессы, в каких отделах организации исполняются конкретные бизнес-процессы?

4. Улучшается взаимосвязь между исполнительными структурами, центрами принятия решений.

5. Способность внедрения корпоративной информационной системы управления и прочее.

Александр Остервальдер и Ив Пинье в своей работе «Построение бизнес-моделей», которая была опубликована в 2011 году, разработали шаблон бизнес-модели как одного из инструментов стратегического анализа, позволяющего исследовать действующие бизнес-процессы в новых и в уже существующих компаниях. Модель-канва позволяет систематизировать и анализировать все бизнес-процессы компании: ценностное предложение, возможности компании, потребителей, каналы сбыта и финансы. В настоящее время помимо разработанной канвы А. Остервальдера и И. Пинье появилось несколько специализированных журналов в этой области, таких как Journal of Business Models (Жур- 
нал бизнес-моделей) и Open Journal of Business Model Innovation (Открытый журнал инноваций бизнес-моделей), которые иллюстрируют новейшие исследовательские тенденции в области бизнес-моделирования.

Интернет-технологии дали возможность топ-менеджменту создавать новые бизнесмодели или заново открывать старые. Электронный бизнес в целом позволил осуществлять операции между компаниями по-новому и без лишних усилий - таким образом, создавая ценность, поскольку Интернет связал компании между собой или с потребителями через новые потоки создания стоимости, потоки доходов или логистические потоки.

Майкл Раппа предложил классификацию онлайновых бизнес-моделей [15], уточнив, что она не является окончательной, так как модели ведения интернет-бизнеса продолжают развиваться. По его мнению особого внимания заслуживают следующие модели:

- Посредническая. Организации получают процент или гонорар за сделки, чаще (биржи, торговое посредничество, платежные системы).

- Рекламная. Доход от демонстрации рекламы или переходы пользователей на сайты рекламодателей.

- Информационная. Доход за счет продажи информации: данных об аудитории.

- Торговая. Непосредственная продажа товаров и услуг.

- Производственная. Выгода производителя товара благодаря сокращению «расстояния» между ним и потребителем.

- Партнерская. Разновидность рекламной модели, где доход приходит от владельцев сайтов-партнеров в обмен на приходящих покупателей.

- Сообщество. Название класса моделей характеризует скорее не источник дохода, а среду, где доход генерируется.

- Подписка. Доход поступает от пользователей, оформляющих подписку на определенные сервисы.

- По потреблению. Клиенту предоставляется определенный сервис, но форма оплаты базируется на потребленном трафике / полученной информации или другом количественном показателе, но не на времени.

Термин «подрывная инновация» связан с появлением лучшей бизнес-модели на устоявшемся рынке. Клейтон Кристенсен исследовал данный вопрос в статье «Изобретите заново свою бизнес-модель», чтобы помочь разобраться разработчикам с этим вопросом. Также в его работе объясняется, как на бизнесе может отразиться появление конкурента. Первоначально следует сделать акцент на ценностное предложение клиенту, затем выявить те элементы в формуле дохода, в процедурах и в ресурсах, которые у конкурента не только совершеннее, но и не доступны для создания аналога. Например, новейшая система продаж, или быстрый оборот товара, или иная тенденция в подходе к производственной модели.

Марк Джонсон в своей работе «Заполняя пустое пространство: инновации в бизнес-модели для роста и обновления» дополнил подход Клейтона Кристенсена, который заключается в усовершенствовании предложенной Кристенсеном классификации с существующими компаниями для более легкого восприятия сути (Таблица 2).

Среди множества различных подходов к классификации бизнес-моделей следует обратить особое внимание на классификацию «Архетипы бизнес-моделей МІТ», которую разработала группа специалистов из Массачуссетского технологического института, и классификацию бизнес-моделей, предложенную Г. Чесбро.

Классификация «Архетипы бизнес-моделей MIT» основывается на 2 главных измерениях бизнеса любой компании: 1. типы прав на активы, продаваемые компанией (здесь можно подчеркнуть 4 базовые бизнес-модели: создатель, дистрибьютор, владелец и брокер), 2. типы активов, вовлеченных в бизнес (следует упомянуть о 4 основных типах активов: физические, финансовые, нематериальные и человеческие). С учетом типов активов в пределах выделенных 4 основных бизнес-моделей выделяются еще по 4 подкатегории моделей. В целом в рамках данной классификации выделяется 16 типов специализированных бизнес-моделей. Из них только 7 получили распространение в крупных компаниях в США. В таблице 3 представлена данная классификация с примерами компаний, которые используют ту или иную модель.

Чесбро, чтобы разделить бизнес-модели по типам, применял всего два показателя их основных отличий: масштаб инвестиций, которые произведены с целью поддержания бизнесмодели и степень открытости модели. Нужно обратиться к Таблице 4, которая представляет классификацию Г.Чесбро с 6 типами бизнесмоделей и примеры компаний.

А.Остервальдер и И.Пиньев книге «Постро- 
Таблица 2. Типология бизнес-моделей Клейтона Кристенсена

\begin{tabular}{|c|c|c|}
\hline Тип & Характеристика & Пример компании \\
\hline Эксклюзивный клуб & $\begin{array}{l}\text { Выплата отчислений крупным организациям } \\
\text { за право продавать свою продукцию исклю- } \\
\text { чительно их клиентам }\end{array}$ & MBNA \\
\hline Брокерство & $\begin{array}{l}\text { Посредничество в сделках между продавцами } \\
\text { и покупателями с целью получения комисси- } \\
\text { онных }\end{array}$ & Century21, Orbitz \\
\hline Пакетирование & $\begin{array}{l}\text { Продажа родственных товаров или услуг } \\
\text { вместе }\end{array}$ & Меню фастфуда, iPod/iTunes \\
\hline Мобильный оператор & $\begin{array}{l}\text { Предложение различных пакетов услуг, ори- } \\
\text { ентированных на разных потребителей. }\end{array}$ & Sprint, BetterPlace \\
\hline Краудсорсинг & $\begin{array}{l}\text { Получение бесплатного контента в обмен на } \\
\text { доступ к другому контенту }\end{array}$ & Wikipedia, YouTube \\
\hline Устранение посредника & $\begin{array}{l}\text { Продажа напрямую, в обход традиционных } \\
\text { схем распределения }\end{array}$ & Dell, WebMD \\
\hline Разделение & $\begin{array}{l}\text { Продажа частичного использования товара } \\
\text { или услуги }\end{array}$ & NetJets, Time-shares \\
\hline Бесплатно - платно & $\begin{array}{l}\text { Основной пакет услуг предоставляется бес- } \\
\text { платно, плата взимается за дополнительные } \\
\text { услуги }\end{array}$ & LinkedIn \\
\hline Лизинг & $\begin{array}{l}\text { Сдача в аренду дорогих товаров с высокими } \\
\text { комиссионными }\end{array}$ & $\begin{array}{l}\text { MachineryLink, машины } \\
\text { премиум-класса }\end{array}$ \\
\hline Лоукостер & Минимальные услуги за минимальную плату & Walmart, IKEA \\
\hline Обратный цикл производства & $\begin{array}{l}\text { Предзаказ товаров и услуг, оплата прежде } \\
\text { получения }\end{array}$ & Amazon \\
\hline Оплата по факту & Взимание платы по счетчику & Электроэнергия \\
\hline Бритва и лезвия & $\begin{array}{l}\text { Продажа товара с высокой себестоимостью с } \\
\text { низкой маржой и доход от продажи расход- } \\
\text { ных материалов }\end{array}$ & $\begin{array}{l}\text { Принтеры и заправка } \\
\text { картриджей }\end{array}$ \\
\hline Бритва и лезвия - наоборот & $\begin{array}{l}\text { Предложение дешевых или бесплатных } \\
\text { расходников, чтобы дорого продать основной } \\
\text { товар }\end{array}$ & AmazonKindle, iPod/iTunes \\
\hline Обратный аукцион & $\begin{array}{l}\text { Торг за право продажи продукта или оказания } \\
\text { услуги, в котором побеждает предложивший } \\
\text { наименьшую цену. }\end{array}$ & Elance.com \\
\hline Товар = услуга & $\begin{array}{l}\text { Продажа не товара, а функции этого товара в } \\
\text { качестве услуги }\end{array}$ & Zipcar \\
\hline Стандартизация & $\begin{array}{l}\text { Стандартизация индивидуальных услуг для } \\
\text { снижения расходов }\end{array}$ & MinuteClinic \\
\hline Подписка & $\begin{array}{l}\text { Взимание абонентской платы за доступ к } \\
\text { услуге }\end{array}$ & Netflix \\
\hline Пользовательские сообщества & $\begin{array}{l}\text { Членский доступ к сети, плата взимается за } \\
\text { доступ и за рекламу }\end{array}$ & Angie’sList \\
\hline
\end{tabular}


Таблица 3. Классификация «Архетипы бизнес-моделей МIT»

\begin{tabular}{|c|c|c|c|c|c|}
\hline \multirow{2}{*}{\multicolumn{2}{|c|}{ Предлагаемая услуга }} & \multicolumn{4}{|c|}{ Типы активов } \\
\hline & & \multirow{2}{*}{\begin{tabular}{l}
\multicolumn{1}{r}{ Физические } \\
Предпринима- \\
тель (серийные \\
предпринима- \\
тель, фирмы- \\
инкубаторы)
\end{tabular}} & \multirow{2}{*}{\begin{tabular}{|l|}
\multicolumn{1}{|c}{ Финансовые } \\
Производитель \\
(General Motors, \\
Bethlehem Steel)
\end{tabular}} & \multirow{2}{*}{$\begin{array}{l}\text { Нематериаль- } \\
\text { ные }\end{array}$} & \multirow{2}{*}{\begin{tabular}{|l}
\multicolumn{1}{|c}{ Человеческие } \\
Создатель и про- \\
давец челове-- \\
ческих ресурсов \\
(нелегальный \\
бизнес) \\
\end{tabular}} \\
\hline Права на активы & $\begin{array}{l}\text { Существенное } \\
\text { преобразование } \\
\text { собственности } \\
\text { (Создатель) }\end{array}$ & & & & \\
\hline & $\begin{array}{l}\text { Ограниченное } \\
\text { преобразование } \\
\text { собственности } \\
\text { (Дистрибьютор) }\end{array}$ & $\begin{array}{l}\text { Финансовый } \\
\text { трейдер (Merrill } \\
\text { Lynch, Goldman } \\
\text { Sachs) }\end{array}$ & $\begin{array}{l}\text { Оптовый про- } \\
\text { давец/ ритей- } \\
\text { лер (Walmart, } \\
\text { Amazon) }\end{array}$ & $\begin{array}{l}\text { IP трейдер (NTL } \\
\text { Inc.) }\end{array}$ & $\begin{array}{l}\text { Дистрибьютор } \\
\text { человеческих } \\
\text { ресурсов (неле- } \\
\text { гальный бизнес) }\end{array}$ \\
\hline & $\begin{array}{l}\text { Использование } \\
\text { (Владелец) }\end{array}$ & $\begin{array}{l}\text { Владелец } \\
\text { финансовых } \\
\text { активов (Bank of } \\
\text { America, Fannie } \\
\text { Mae, Aetna, } \\
\text { Chubb) }\end{array}$ & $\begin{array}{l}\text { Владелец физи- } \\
\text { ческих активов } \\
\text { (Marriott, Hertz } \\
\text { division of Ford) }\end{array}$ & $\begin{array}{l}\text { Владелец нема- } \\
\text { териальных ак- } \\
\text { тивов (Microsoft, } \\
\text { Wendy’s, New } \\
\text { York Times) }\end{array}$ & $\begin{array}{l}\text { Контрактор } \\
\text { (Accenture, } \\
\text { Federal Express) }\end{array}$ \\
\hline & $\begin{array}{l}\text { Подбор в } \\
\text { соответствие } \\
\text { с запросами } \\
\text { (Брокер) }\end{array}$ & $\begin{array}{l}\text { Брокер по } \\
\text { финансовым } \\
\text { активам (eTrade, } \\
\text { Schwab) }\end{array}$ & $\begin{array}{l}\text { Брокер по физи- } \\
\text { ческим активам } \\
\text { (eBay, Priceline) }\end{array}$ & $\begin{array}{l}\text { IP брокер } \\
\text { (Valassis) }\end{array}$ & $\begin{array}{l}\text { Брокер по } \\
\text { человеческим } \\
\text { ресурсам (Robert } \\
\text { Half, EDS) }\end{array}$ \\
\hline
\end{tabular}

Источник: https://www.cfin.ru/management/controlling/business_model.shtml

Таблиц̧а 4. Классификация бизнес-моделей Г. Чесбро

\begin{tabular}{|l|l|}
\hline \multicolumn{1}{|c|}{ Тип бизнес-модели } & \multicolumn{1}{|c|}{ Пример компании } \\
\hline Недифференцированная & Семейные рестораны \\
\hline Дифференцированная & Начинающие технологические компании \\
\hline Сегментированная & Компании, продвигающие какую-либо технологию \\
\hline Внешне ориентированная & $\begin{array}{l}\text { Компании, специализирующиеся на НИОКР и дей- } \\
\text { ствующие в зрелых отраслях }\end{array}$ \\
\hline Интегрированная с инновационным процессом & Bедущие финансовые компании \\
\hline Адаптивная & Intel, Wal-Mart, Dell \\
\hline
\end{tabular}

Источник: https://www.cfin.ru/management/controlling/business_model.shtml

ение бизнес-моделей. Настольная книга стратега и новатора» проиллюстрировали бизнесмодели с похожими характеристиками, сходной структурой или подобным поведением. Авторы анализируют такие модели как сосредоточение определенного стиля действия. Они выделили 5 стилей, основываясь на идеях, которые были описаны в бизнес-литературе. Основа их выделения - это идеи разделения, «длинного хвоста», многосторонних платформ, FREE и открытых бизнес-моделей. Как авторы отмечают, могут появиться новые стили как результат времени и могут основываться на совершенно иных концепциях. Классификация моделей с включением примеров компаний представлена в таблице 5.

Несмотря на многоплановость подходов к классификации, бизнес-модель существует для отражения особенного набора внутренних ресурсов и способностей компании, а также определенные методы их взаимодействия, образовывающие кластеры инновационных продуктов и стимулирующих появление конкурентного превосходства. Поэтому обзор разработки и реализации бизнес-моделей на практике иллюстрирует, их создание приурочено к особому продукту или услуге, для одной компании, либо для группы компаний. Важно подчеркнуть, что внутренние ресурсы и способности - база для разработки долгосрочной перспективной стратегии. В конечном счете помогают компании увеличить ценность для потребителя и не потерпеть крах в условиях конкурентной борьбы. 
Таблица 5. Стили бизнес-моделей А. Остервальдера и И.Пинье

\begin{tabular}{|c|c|c|c|}
\hline Стили & Концепция & Описание стиля & $\begin{array}{c}\text { Примеры ком- } \\
\text { паний }\end{array}$ \\
\hline Стиль № 1 & $\begin{array}{l}\text { Разделение } \\
\text { бизнес-модели }\end{array}$ & $\begin{array}{l}\text { Существует } 3 \text { основных формы бизнеса: управление взаи- } \\
\text { моотношениями с клиентами, инновационные продукты } \\
\text { и управление инфраструктурой. У каждой из них свои эко- } \\
\text { номические, конкурентные и культурные правила. Несмо- } \\
\text { тря на возможное сосуществование трех форм в рамках } \\
\text { одной компании, их следует разделять, чтобы исключить } \\
\text { нежелательное влияние. }\end{array}$ & $\begin{array}{l}\text { MaerkiBaumann, } \\
\text { частные банки, } \\
\text { компании мо- } \\
\text { бильной связи }\end{array}$ \\
\hline Стиль № 2 & Длинный хвост & $\begin{array}{l}\text { Предложение большого количества нишевых товаров, каж- } \\
\text { дый из которых продается относительно редко. Не требует } \\
\text { больших складских издержек, необходима прочная плат- } \\
\text { форма для быстрой доставки клиентам товаров. }\end{array}$ & $\begin{array}{l}\text { Netflix, eBay, } \\
\text { YouTube, } \\
\text { Facebook, Lulu. } \\
\text { com, LEGO }\end{array}$ \\
\hline Стиль № 3 & $\begin{array}{l}\text { Многосторонние } \\
\text { платформы }\end{array}$ & $\begin{array}{l}\text { Объединение } 2 \text { или более разных, но каким-либо обра- } \\
\text { зом связанных групп потребителей. Создание ценности } \\
\text { благодаря развитию взаимодействия между группами. } \\
\text { Ценность многосторонней платформы растет, пока все } \\
\text { большее число клиентов ею заинтересовано (сетевой } \\
\text { эффект). }\end{array}$ & $\begin{array}{l}\text { Visa, Google, } \\
\text { eBay, Microsoft } \\
\text { Windows }\end{array}$ \\
\hline Стиль № 4 & FREE & $\begin{array}{l}\text { Модель, по которой в течение долгого времени значи- } \\
\text { тельный сегмент потребителей может получать выгоду от } \\
\text { бесплатного предложения. Финансирование потребителей } \\
\text { происходит за счет другой части бизнес-модели или дру- } \\
\text { гим потребительским сегментом. }\end{array}$ & $\begin{array}{l}\text { Меtro (бес- } \\
\text { платнаягазета), } \\
\text { Flickr, Open } \\
\text { Source, Skype, } \\
\text { Google, Free } \\
\text { Mobile Phones }\end{array}$ \\
\hline Стиль № 5 & $\begin{array}{l}\text { Открытые } \\
\text { бизнес-модели }\end{array}$ & $\begin{array}{l}\text { Полезны для создания и сохранения ценности с помощью } \\
\text { сотрудничества с внешними партнерами. Возможно либо } \\
\text { использование внешних идей, либо предоставление внеш- } \\
\text { ним партнерам идей, не востребованных самой фирмой. }\end{array}$ & $\begin{array}{l}\text { P\&G, } \\
\text { GlaxoSmithKilne, } \\
\text { Innocentive }\end{array}$ \\
\hline
\end{tabular}

Источник: Остервальдер А., Пинье Ив. Построение бизнес-моделей. Настольная книга стратега и новатора. М.: Альпина Паблишер, 2013.- 288 с.

\section{Заключение}

«Бизнес-модель», как мы считаем, должна являться залогом успешного бизнеса при этом остается системой, означающей сложный и структурированный подход. Мы только полагаем, что рецепт успеха можно взять у таких компаний, как Apple, Amazon, Facebook или Twitter, и примерить к другим организациям, что приве- дет к грандиозному успеху. Каждая из этих компаний достигла успеха своим способом, методом и не найти единого пути развития, который подходит для любой бизнес-модели. Следовательно, вопрос ученых и практиков заключается в том, как определенная компания может выработать свою формулу успеха. Такие основополагающие вопросы до сих остаются без ответа.

\section{Библиографический список}

1. Пять успешных бизнес-моделей [Электронный ресурс] - Режим доступа.- URL: http: //www.francon.ru/ area_news/26 (дата обращения: 02.10.2015).

2. Горевая Е. С. Управление бизнес-моделью: становление концепции и современные тренды // Российское предпринимательство.-2017.- Т. 17. - № 16.- С. 1925-1944

3. Стрекалова Н.Д. Бизнес-модель как полезная концепция стратегического управления // Проблемы современной экономики. - 2009.- № 2.- С. 133-137.

4. Hamel G., Prahalad K. Competing for the Future.- Boston: Harvard Business Review Press, 1996. - 384 p.

5. Джонсон М., Кристенсен К., Кагерманн Х. Обновление бизнес-модели // HarvardBusinessReview.-2009.№ $3 .-$ C. 63.

6. Linder J., Cantrell S. Changing Business Models: Surveying the Landscape [Electronic resource] // Shanghai University of Finance and Economics. - 2000.- Mode of access: http://course.shufe.edu.cn/jpkc/zhanlue/upfiles/ edit/201002/20100224120954.pdf 
7. Стрекалова Н.Д. Концепция бизнес-модели: методология системного анализа // Известия Российского государственного педагогического университета им. А. И. Герцена. - 2009. - № 92.- С. 95-105.

8. Третьяк О.А., КлимановД.Е. Новый подход к анализу бизнес-моделей // Российский журнал менеджмента. - 2016. - Т. 14. - № 1.- С. 115-130.

9. Трачук А.В., ЛиндерН.В., АнтоновД.А. Влияние информационно-коммуникационных технологий на бизнес-модели современных компаний // СРРМ. 2014. № 5 (86)

10. Chesbrough $H$. Business model innovation: It's not just about technology anymore. Strategy and Leadership, 2007, Vol. 35, No. 6.

11. Christensen C.M., Kagermann H. Reinventing your business model. Harvard Business Review, 2008, Vol. 86, No. 12 .

12. Чан Ким У., Моборн Р. Стратегия голубого океана.- М: Манн, Иванов и Фербер, 2013. - 304 с.

13. Дебелак Д.Бизнес-модели: Принципы создания процветающей организации.- М: ИД «Гребенников», 2009. - 256 с.

14. Климанов Д.Е., Третьяк О.А. Бизнес-модели: основные направления исследований и поиски содержательного фундамента концепции // Российский журнал менеджмента. - 2014. - Т. 12. - № 3. - C. $107-130$.

15. Rappa M. Managing the digital enterprise - Business models on the Web, North Carolina State University, 2001. 